\title{
Application of Luminescent Metal-Organic Frameworks for Chemical Sensing
}

\author{
Xinhui Zhou* and Yali Zhu \\ Key Laboratory for Organic Electronics and Information Displays \& Institute of Advanced Materials, \\ Nanjing University of Posts \& Telecommunications, Nanjing, Jiangsu 210023, China
}

\begin{abstract}
Nowadays, there has been an enormous demand for chemical sensors to detect a variety of analytes for a range of applications, including homeland security guarding, exploration of mineral resources, meteorological observation and telemetry, industrial automation, agricultural fresh preservation, environment monitoring and food quality controlling. Metal-organic frameworks are a new class of porous materials, which are formed by the assembly of metal ions with functional organic ligands. They have attracted great attention in chemical sensing owing to their suitable porosity, specific functional groups, higher quantum yield and tunable luminescent properties. This review summarizes some examples of the application of luminescent metal-organic frameworks for sensing of nitro explosives, metal ions, small molecules, $\mathrm{pH}$ value and temperature.
\end{abstract}

Keywords metal-organic frameworks, luminescent, sensing

\section{Introduction}

Nowadays, there has been enormous demand for chemical sensors to detect a variety of analytes for a range of applications, including homeland security guarding, exploration of mineral resources, meteorological observation and telemetry, industrial automation, agricultural fresh preservation, environment monitoring, and food quality controlling. Typically, chemical sensors can bind selectively and reversibly the experimental analytes of interest with a concomitant change in electrical, optical, or mechanical properties. ${ }^{[1]}$ Among all the chemosensors, luminescence-based ones make use of changes of a fluorescent probe material in the photoluminescence to detect the presence of an analyte or target condition, and they are within the most desirable transduction mechanisms due to its relative ease of use, technical simplicity, and broad adaptability. ${ }^{[2]}$ However, there still remain some challenges to realize better sensory performance including increased brightness, longer fluorescent life, higher quantum yield and multifunctional systems. Therefore, it is necessary to search for a particular class of materials as luminescent sensors to construct a robust platform to deal with these challenges.

Over the last two decades, metal-organic frameworks (MOFs) are a new class of porous materials, which are formed by the assembly of metal ions with functional organic ligands. ${ }^{[3]}$ They have attracted great attention owing to their extensive applications in a wide areas such as light emitting, ${ }^{[4]}$ chemical sensing, ${ }^{[5]}$ gas storage and separation, ${ }^{[6]}$ heterogeneous catalysis, ${ }^{[7]}$ drug delivery, ${ }^{[8]}$ and magnetic properties. ${ }^{[9]}$ Among them, some luminescent MOFs are utilized for chemical sensing mostly based on the photoluminescence and tunable porous structure. ${ }^{[10]}$ The reason is as follows: Firstly, the functional sites in MOFs such as Lewis basic/acidic sites and unsaturated metal sites can be used for selective recognition of targeted molecules/ions; Secondly, the tunable porosity can enable the reversible storage of guest species, making MOFs both as detection and pre-concentrator medium. Clearly, MOFs are a great kind of materials in their development with respect to chemical sensing.

In this review, we will give a detailed introduction of the application of luminescent MOFs for sensing of nitro explosives, metal ions, small molecules, $\mathrm{pH}$ value and temperature.

\section{Sensing applications}

\section{Sensing of nitro explosives}

Nitro explosives, widely used in industrial processing on a large scale, are highly explosive molecules. During synthesis, processing and disposal, nitro explosives are released into the environment, especially to water streams, contaminating ground and surface water. Luminescent MOF materials have been utilized for effective detection of high nitro explosives. Zhang et al. reported a compound $\{[\mathrm{Tb}$ (Hbzptc) $]_{2} \cdot$ bpp $\left.2 \mathrm{H}_{2} \mathrm{O}\right\}_{n}$ (1) $\left(\mathrm{H}_{4}\right.$ bzptc=benzophenone-3,3',4,4'-tetracarboxylic acid, bpp=1,2-di(4-pyridyl)ethane), as shown in Figure 1. Compound 1 has the sensitive detection for the trace content of nitrobenzene with $5.5 \times 10^{-5} \mathrm{M}$. The Stern-Volmer plots of the relative luminescent intensity $\left(I_{0} / I\right)$ versus the nitrobenzene concentration, where $I_{0}$ and $I$ are the luminescent intensities of compound $\mathbf{1}$ before and after adding nitrobenzene, respectively. Nonlinear Stern-Volmer curves can be well-fitted by the exponential equations of $I_{0} / I=$ $1.72 \mathrm{e}^{57700[\mathrm{NB}]}-0.72$ with quenching constant of $9.92 \times 10^{4}$ in the low concentration range. ${ }^{[11]}$ Wang et al. explored systematically the fluorescence sensing responses of $\left[\mathrm{Cd}_{2}\left(\mathrm{H}_{2} \mathrm{~L}\right)_{2}\left(\mathrm{H}_{2} \mathrm{O}\right)_{5}\right] \cdot 5 \mathrm{H}_{2} \mathrm{O} \cdot 2 \mathrm{DMF}$ (2) $\left[\mathrm{H}_{4} \mathrm{~L}=2,5\right.$-bis-(3,5-dicarboxyphenyl)thiopheneamide] to small organic molecules. Notably, complex 2 can act as a potential multifunctional fluorescence material for sensing of $p$-nitroaniline ion with high stability, selectivity and sensitivity (Figure 2$){ }^{[12]}$ Zhou et al. reported a compound $\left[\mathrm{Eu}_{2} \mathrm{~L}\left(\mathrm{H}_{2} \mathrm{~L}\right)(\mathrm{NMP})_{2}\right] \cdot \mathrm{H}_{2} \mathrm{O}$ (3) $\left(\mathrm{H}_{4} \mathrm{~L}=1,1^{\prime}: 4\right.$ ', 1 "-terphenyl2',4,4",5'-tetracarboxylic acid; NMP $=N$-methyl-2-pyrroli-done), which has fluorescent quenching response towards the aromatic nitro compounds, especially for the 3,4-dinitrotoluene (3,4-DNT) with the linear Stern-Volmer relationship in the concentration range of $0-1$ $\mathrm{mM}$ and the quenching constant $\left(K_{\mathrm{sv}}\right)$ of $2.084 \times 10^{3} \mathrm{M}^{-1}$ (Figure 3$){ }^{[13]}$ Zhu et al. reported a MOF $\left[\mathrm{Cd}(\text { cis-chdc })(\text { anti-bpe })\left(\mathrm{H}_{2} \mathrm{O}\right)\right]_{n}$ (4) $\left[\mathrm{H}_{2} \mathrm{chdc}=1,4\right.$-cyclohexanedicarboxylic acid, bpe=1,2-bis(4-pyridyl)ethane], the excellent ability of $\mathbf{4}$ for selective detection of 4-nitrotoluene from other nitroaromatic compounds has been demonstrated (Figure 4). The recyclability and reusability of $\mathbf{4}$ have also been tested based on consecutive detection reactions, in which 4 remains unchanged and detection efficiency retains. ${ }^{[14]}$ 


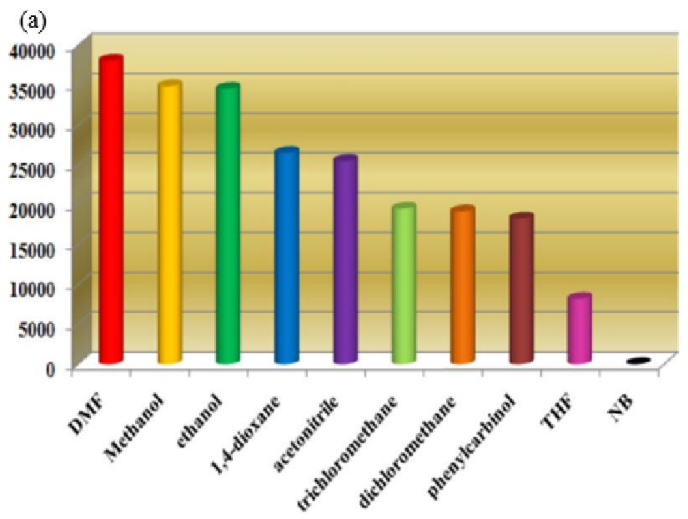

(b)

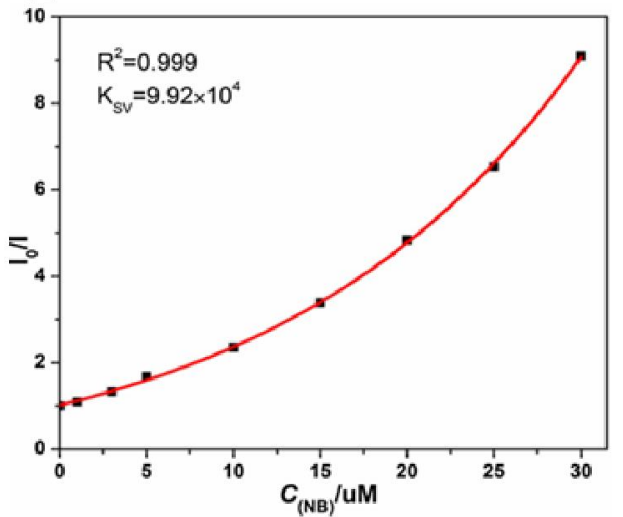

Figure 1 (a) Comparison the luminescence intensity of $\mathbf{1}$ dispersed into different solvents when excited at $355 \mathrm{~nm}$; (b) Stern-Volmer plots of $I_{0} / I$ versus the nitrobenzene concentration.
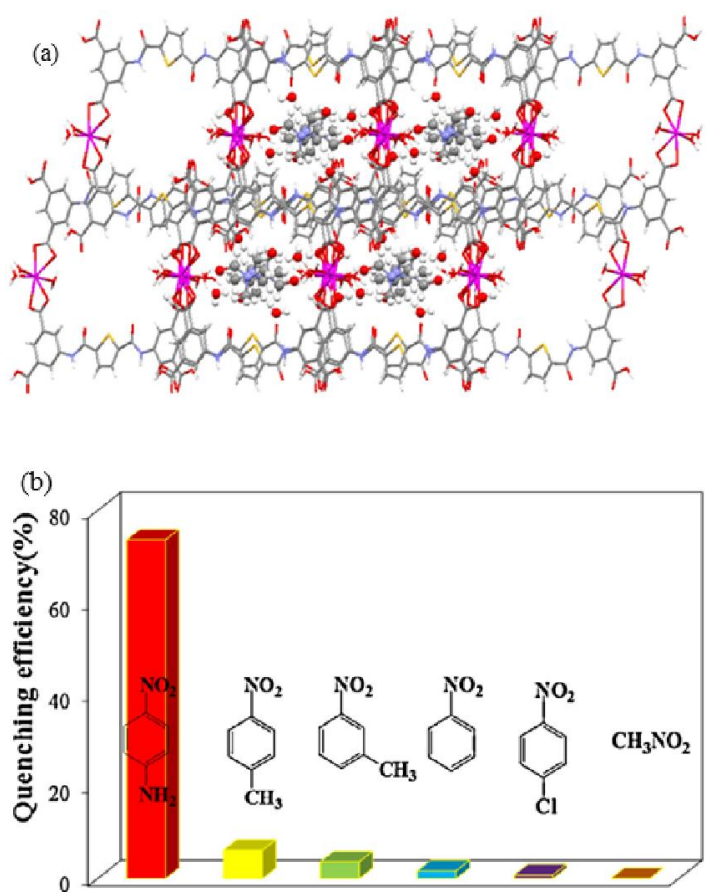

Figure 2 (a) The 3D supramolecular network of 2; (b) Percentage of fluorescence quenching of $\mathbf{2}$ obtained for different analytes in isopropanol solution at room temperature.
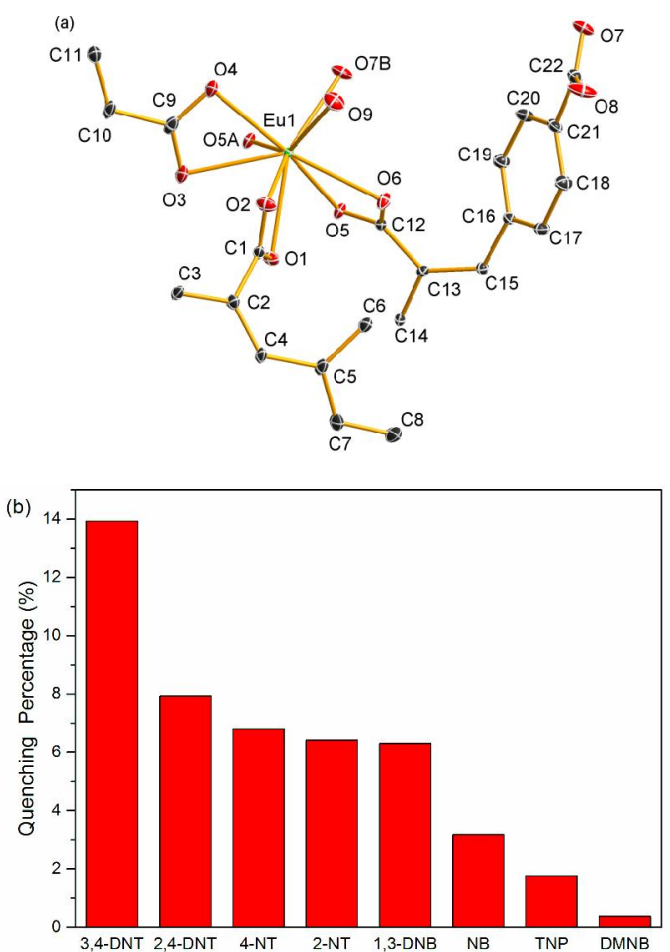

Figure 3 (a) View of the asymmetric unit of $\mathbf{3}$ with the thermal ellipsoids drawn at the $30 \%$ probability level; (b) Luminescence quenching percentages when 3 was dispersed in eight different nitro compounds in DMF (excited and monitored at $340 \mathrm{~nm}$ and $617 \mathrm{~nm}$, respectively).

(a)

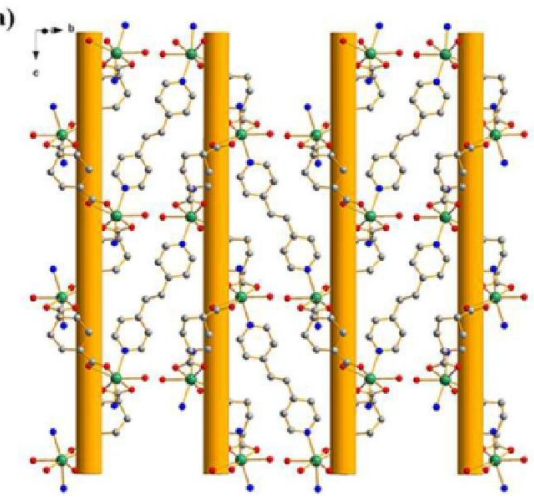

(b)

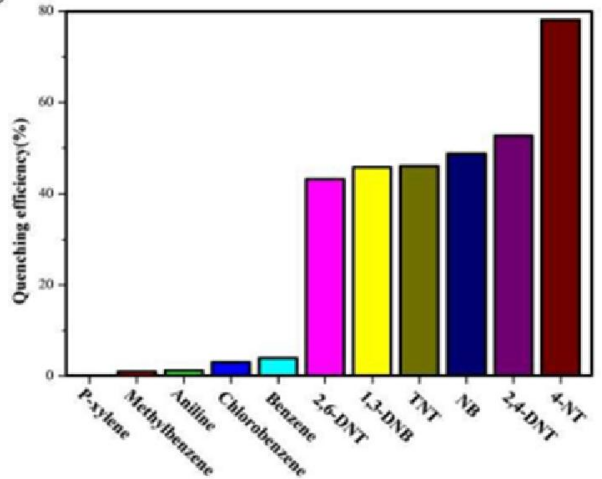

Figure 4 (a) View of the two-dimensional helical structure of 4; (b) Fluorescence intensity ratio histograms of 4 upon exposure to 0.3 $\mathrm{mM}$ concentration of different analytes. 


\section{Sensing of metal ions}

\section{Sensing of $\mathrm{Fe}^{3+}$ ion}

The first photoluminescent $\mathrm{Cd}(\mathrm{II})$-organic framework $\{[\mathrm{Cd}(5-$ asba)(bimb)] $\}_{n}$ (5) based on a multi-functional ligand 2-amino-5sulfobenzoic acid $\left(\mathrm{H}_{2} 5\right.$-asba) has been successfully constructed. Photoluminescent properties of $\mathbf{5}$ indicated that $\mathbf{5}$ belongs to the rare category of MOFs that exhibits the multi-responsive photoluminescence sensing properties. It can be used as a rapid and efficient selective fluorescence sensor for $\mathrm{Fe}^{3+}$ ions in environment and biological system at about one ppm level (Figure 5). ${ }^{[15]}$ Two stable MOFs, $\left[\mathrm{Zr}_{6} \mathrm{O}_{4}(\mathrm{OH})_{8}\left(\mathrm{H}_{2} \mathrm{O}\right)_{4}\left(\mathrm{~L}^{1}\right)_{2}\right](\mathrm{BUT}-14)$ and $\left[\mathrm{Zr}_{6} \mathrm{O}_{4}(\mathrm{OH})_{8}\left(\mathrm{H}_{2} \mathrm{O}\right)_{4}-\left(\mathrm{L}^{2}\right)_{2}\right]$ (BUT-15) were designed and synthesized for the detection of metal ions in water. Two new ligands utilized for construction of the MOFs, namely, 5',5'"-bis(4-carboxyphenyl)-[1,1':3',1":4", $1^{\prime \prime \prime}: 3^{\prime \prime \prime}, 1^{\prime \prime \prime \prime}$ -quinquephenyl]-4,4"''-dicarboxylate $\left(\mathrm{L}^{1}\right)$ and 4,4',4",4"'-(4,4'-(1,4phenylene)bis(pyridine-6,4,2-triyl))tetrabenzoate $\left(\mathrm{L}^{2}\right)$. Interestingly, they show intense fluorescence in water, which can be solely quenched by trace amounts of $\mathrm{Fe}^{3+}$ ions. The detection limits towards the $\mathrm{Fe}^{3+}$ ions were calculated to be 212 and $16 \mathrm{ug} / \mathrm{L}$, respectively. The efficient fluorescent quenching effect is attributed to the photoinduced electron transfer between $\mathrm{Fe}^{3+}$ ions and the ligands in these MOFs (Figure 6) ${ }^{[16]}$ Ming et al. reported a $\mathrm{Pb}(\mathrm{II})-\mathrm{Na}(\mathrm{I})$ coordination polymer, $\left\{\left[\mathrm{Pb}_{3} \mathrm{NaL}_{3}\right]\left(\mathrm{Me}_{2} \mathrm{NH}_{2}\right)_{2}\left(\mathrm{C}_{2} \mathrm{H}_{5} \mathrm{OH}\right)_{1.5}\left(\mathrm{H}_{2} \mathrm{O}\right)_{10.5}\right\}_{n}$ (6) $\left(\mathrm{H}_{3} \mathrm{~L}=\right.$ 4,4',4"-s-triazine-2,4,6-triyl-tribenzoic acid). Luminescent investigations reveal that $\mathbf{6}$ can detect $\mathrm{Fe}^{3+}$ with relative high sensitivity and selectivity, and show broad linear range of $0-1000 \mu \mathrm{M}$, as well as low detection limits of $8.65 \mathrm{nM}$ for $\mathrm{Fe}^{3+} \cdot[17]$ The sensing properties of Zr-based MOF structure UiO-66-BI towards different ions were studied, and the results demonstrated that UiO-66-BI showed excellent selective luminescent sensing of $\mathrm{Fe}^{3+}$ ions in water. ${ }^{[18]}$ Otherwise, $\mathrm{Cd}(\mathrm{II})-\mathrm{MOFs}^{\left[1{ }^{[9]}\right.}\left[\mathrm{H}_{2} \mathrm{~N}(\mathrm{Me})_{2}\right]\left[\mathrm{Eu}_{3}(\mathrm{OH})(\mathrm{bpt})_{3}\left(\mathrm{H}_{2} \mathrm{O}\right)_{3}\right](\mathrm{DMF})_{2}$ $\cdot\left(\mathrm{H}_{2} \mathrm{O}\right)_{4},{ }^{[20]} \quad\left[\mathrm{Eu}(\mathrm{HL})(\mathrm{DMF})\left(\mathrm{H}_{2} \mathrm{O}\right)_{2}\right] \cdot 3 \mathrm{H}_{2} \mathrm{O}, \quad[\mathrm{Tb}(\mathrm{HL})(\mathrm{DMF})$ $\left.\left(\mathrm{H}_{2} \mathrm{O}\right)_{2}\right] \cdot 3 \mathrm{H}_{2} \mathrm{O} \quad\left(\mathrm{H}_{4} \mathrm{~L}=2,8,14,20\right.$-tetra-ethyl-6,12,18, 24-tetra-methoxy$4,10,16,22$-tetra-carboxy-methoxy-calix[4]arene ${ }^{[21]}$ and $\left[\mathrm{Eu}_{2}(\mathrm{FDC})_{3^{-}}\right.$ $\left.\operatorname{DMA}\left(\mathrm{H}_{2} \mathrm{O}\right)_{3}\right] \cdot$ DMA $4.5 \mathrm{H}_{2} \mathrm{O} \quad\left(\mathrm{H}_{2} \mathrm{FDC}=9,9\right.$-dimethyl-2,7-fluorenedicarboxylic acid, DMA=dimethylacetamide $)^{[22]}$ also display highsensitivity for $\mathrm{Fe}^{3+}$.
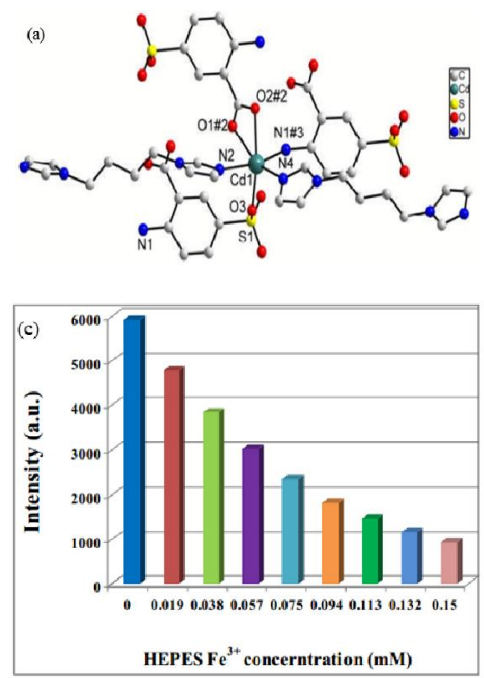

Figure 5 (a) Coordination environment of the $\mathrm{Cd}(\mathrm{II})$ ion in $\mathbf{5}$, also showing the trans-trans-trans conformation of bimb. Symmetry codes: $\# 2-x+2,-y+1,-z+1 \# 3 x-1, y, z$; (b) The relative maximum emission intensity of 5 by introducing different metal ions with thesame concentration of $0.075 \mathrm{mM}$ in the final mixture $\left(\lambda_{\mathrm{ex}}=300 \mathrm{~nm}\right)$; (c) The maximum intensity (Bottom) of $\mathbf{5}$ dispersed in HEPES aqueous buffer solution $(\mathrm{pH}=7)$.
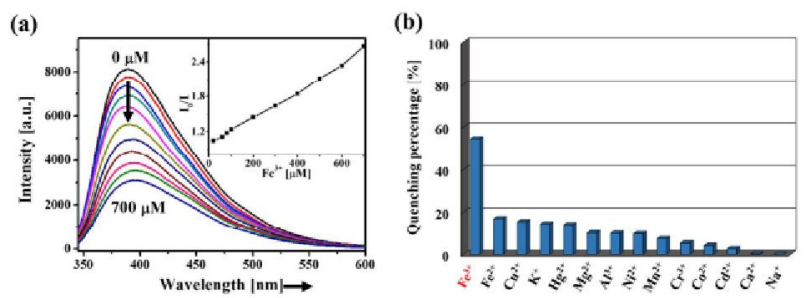

(c)

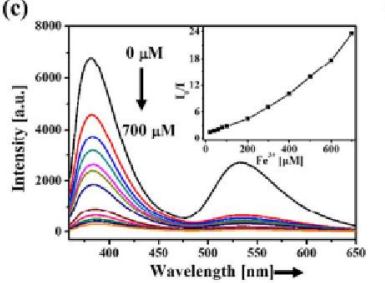

(d)

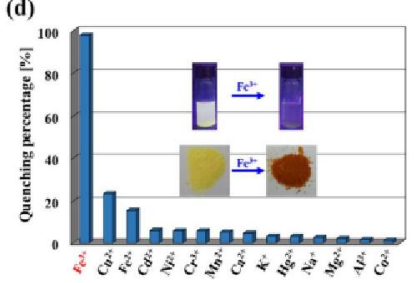

Figure 6 Fluorescent spectra of (a) BUT-14 and (c) BUT-15 in water in the presence of different concentrations of $\mathrm{Fe}\left(\mathrm{NO}_{3}\right)_{3}$ under excitation at 330 and $320 \mathrm{~nm}$, respectively (Inset: SV plots of $\mathrm{Fe}^{3+}$ ions); Fluorescent quenching percentage of (b) BUT-14 and (d) BUT-15 in water by $1 \mathrm{mM}$ different metal ions under excitation at 330 and $320 \mathrm{~nm}$, respectively, at room temperature (Inset: photographs of BUT-15 andBUT-15-Fe ${ }^{3+}$ samples in water under UV light of $365 \mathrm{~nm}$, and photographs of them as solid).

\section{Sensing of $\mathrm{Cu}^{2+}$ ion}

The 2,2'-bipyridyl moieties lining the channels of two designermetal-organic frameworks, UiO-bpydc and Eu-bpydc (bpydc is 2,2'-bipyridine 5,5'-dicarboxylic acid), recognize and preconcentrate metal ion analytes, and in the case of Eu-bpydc, transfer energy to the $\mathrm{Eu}^{3+}$ centers, to provide highly sensitive luminescent sensors for transition metal ions (Figure 7). Comparing the sensitivities of the UiO-bpydc and Eu-bpydc towards the same metal ion, significant difference can also be identified. Inparticularly, $\mathrm{Cu}^{2+}$ gives a relatively high quenching response in the Eu-bpydc MOF, but not in UiO-bpydc. ${ }^{[23]}$ Photoluminescence measurement of a novel neodymium-organic framework (Nd-MOF) based on $\mathrm{Nd}(\mathrm{III})$ dinuclear nodes, with formula $\left\{\left[\mathrm{Nd}_{2}\left(\mathrm{NH}_{2}-\mathrm{BDC}\right)_{3}(\mathrm{DMF})_{4}\right]\right\}_{n}(7)\left(\mathrm{NH}_{2}-\mathrm{BDC}=\right.$ 2-aminoterephthalic acid) indicates that 7 exhibits excellent near infrared luminescence. In addition, 7 displays rapid and selective sensing of $\mathrm{Cu}^{2+}$ (Figure 8), ${ }^{[24]}$ which represents the first near infrared fluorescent probe of MOFs used for detection. $\left[\mathrm{H}_{2} \mathrm{~N}(\mathrm{Me})_{2}\right]-$ $\left[\mathrm{Eu}_{3}(\mathrm{~L})_{2}(\mathrm{HCOO})_{2}(\mathrm{DMF})_{2}\left(\mathrm{H}_{2} \mathrm{O}\right)\right]\left[\mathrm{H}_{4} \mathrm{~L}=2,6\right.$-di(30,50-dicarboxylphenyl)pyridine] also reveals high luminescent selectivity and sensitivity for $\mathrm{Cu}^{2+}$ ions as a result of weak contacts between pyridyl sites in $\mathrm{L}^{4-}$ and $\mathrm{Cu}^{2+} \cdot{ }^{[25]}$

\section{Sensing of $\mathrm{Ag}^{+}$ion}

The $\mathrm{Sm}^{3+}$-doped MOF has been used for highly sensitive sensing of $\mathrm{Ag}^{+}$, and the weak fluorescence of $\mathrm{Sm}^{3+}$-doped MOF was greatly enhanced by $\mathrm{Ag}^{+} .^{[26]}$ Besides, a robust gallium carboxylate $\mathrm{Ga}(\mathrm{OH})(\mathrm{btec}) \cdot 0.5 \mathrm{H}_{2} \mathrm{O}$ (MIL-61) is selected as parent MOF to prepare Ln-MIL-61 by PSMs. The weak fluorescence of $\mathrm{Sm}^{3+}$ or $\mathrm{Dy}^{3+}$ doped MIL-61 is effectively sensitized by $\mathrm{Ag}^{+}$. Furthermore, the Sm-MIL61 shows more highly sensitive and selective sensing towards $\mathrm{Ag}^{+}$, which is a promising optical sensor for $\mathrm{Ag}^{+}$detection in several of daily water samples. ${ }^{[2]}$ Otherwise, a new approach inspired by fluorescent labeling technology to fluorescently functionalize MOFs via post-modification is reported. A fluorescein-containing MOF FITC@ BTPY-NH $\mathrm{N}_{2}$ was synthesized for selective sensing and adsorption of $\mathrm{Ag}^{+}$in aqueous solution. ${ }^{[28]}$ 


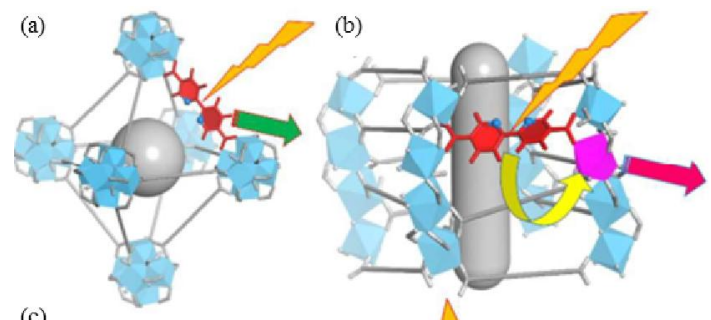

(c)

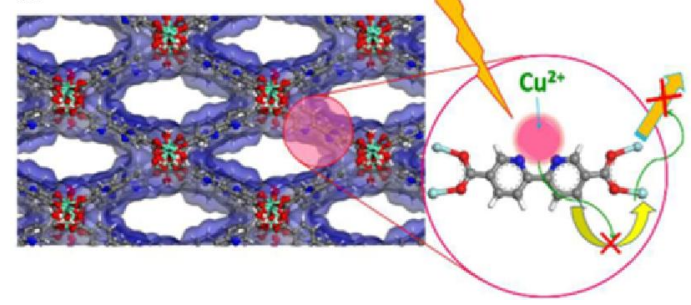

Figure 7 The crystal structure of the two MOFs with free bpymoieties in the channel. (a) UiO-bpydc; (b) and (c) Eu-bpydc; scheme in the figures also showed how the metal chelation interrupts energy transfer and emission.
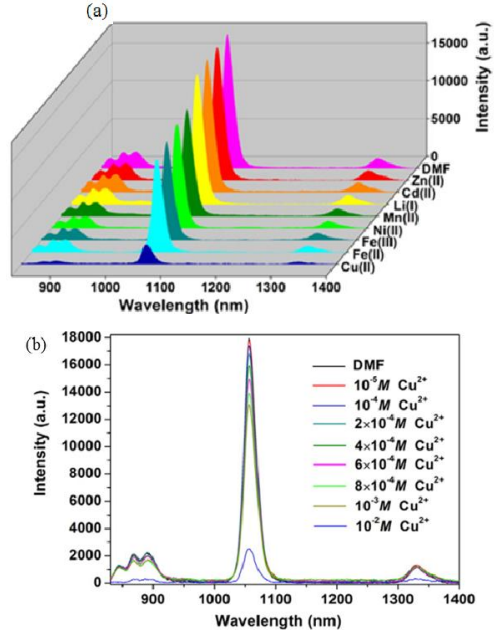

Figure 8 (a) The luminescence spectra of 7 dispersed into different metal ions $\mathrm{M}^{2+}$ DMF solution; (b) The NIR luminescence spectra of 7 immersed in DMF solutions with different concentrations of $\mathrm{CuCl}_{2}$ (excited at $808 \mathrm{~nm}$ by laser).

\section{Sensing of other metal ions}

A novel 3D microporous compound $\left[\mathrm{Zn}_{3}(\mathrm{Httca})_{2}(4,40-\mathrm{bpy})-\right.$ $\left.\left(\mathrm{H}_{2} \mathrm{O}\right)_{2}\right]_{n}(\mathrm{MOF}-\mathrm{COOH})$ containing uncoordinated carbonyl groups pointing to the pores was prepared. The uncoordinated carbonyl groups inthe channels can act as postsynthetic modification sites forcation exchange. The MOF-COOH compound can serve effectively and selectively as an antenna for sensitizing the visible-emitting $\mathrm{Tb}^{3+}$ cation. $^{[29]}[\mathrm{Zn}(p \text {-TIPhHIDC })]_{n}$, bearing two novel substituted imidazoledicarboxylate ligands, 2-( $p-N$-imidazol-1-yl)phenyl- $1 H$-imidazole-4,5dicarboxylic acid $\left(p\right.$ - IPhH $_{3}$ IDC) and 2-p-(1H-1,2,4-triazol-1-yl)-phenyl-1 $H$-imidazole-4,5dicarboxylic acid $\left(p-\mathrm{TIPhH}_{3} \mathrm{I}-\mathrm{DC}\right)$ shows good luminescent sensing of $\mathrm{K}^{+}{ }^{[30]}$ Two novel pillared MOFs $\left[\mathrm{Zn}_{2}(\operatorname{trz})_{2}(\mathrm{tda})\right] \cdot \mathrm{DMA} \mathrm{CH} \mathrm{CH}_{3} \mathrm{OH}$ and $\left[\mathrm{Zn}_{2}(\operatorname{trz})_{2}-\right.$ (bpdc)]·DMA $\quad\left(\mathrm{H}_{2} \mathrm{tda}=(2,5\right.$-thiophenedicarboxylic acid, $\mathrm{H}_{2}$ bpdc $=4,4$ '-di-phenyldicarboxylicacid) were obtained under solvothermal condition and displayed a certain degree of framework stabilities in both acid/base solutions and water. The luminescence intensity of their activated phase are sensitive to metal ions, particularly $\mathrm{Cd}^{2+}$ ions. $^{[31]}$ A new superstable, anionic terbium-metal-organic- framework, $\left[\mathrm{H}_{2} \mathrm{~N}\left(\mathrm{CH}_{3}\right)_{2}\right]\left[\mathrm{Tb}(\mathrm{cppa})_{2}\left(\mathrm{H}_{2} \mathrm{O}\right)_{2}\right], \quad\left(\mathrm{H}_{2}\right.$ cppa $=5$-(4-carboxyphenyl)picolinicacid), is successfully prepared, which can be used as a turn-on, highly-sensitive fluorescent sensor to detect $\mathrm{Eu}^{3+}$ and $\mathrm{Dy}^{3+}$, with a detection limitation of $5 \times 10^{-8}$ and $1 \times 10^{-4} \mathrm{M}$ in dimethyl formamide, respectively. ${ }^{[32]}$

\section{Sensing of gas molecules}

\section{Sensing of $\mathrm{H}_{2} \mathrm{~S}$}

The azide $\left(\mathbf{1}-\mathbf{N}_{\mathbf{3}}\right)$ and nitro $\left(\mathbf{2}-\mathbf{N O}_{\mathbf{2}}\right)$ functionalized Ce MOFs have been synthesized under similar solvothermal conditions using ammonium cerium(IV) nitrate and $\mathrm{H}_{2} \mathrm{BDC}-\mathrm{X}(\mathrm{BDC}=1$,4-benzenedicarboxylate; $X=-\mathrm{N}_{3}$ for $\mathbf{1}-\mathrm{N}_{3}$ and $-\mathrm{NO}_{2}$ for $\left.\mathbf{2}-\mathrm{NO}_{2}\right)$. The thermally activated forms of both compounds $\left(\mathbf{1}-\mathbf{N}_{\mathbf{3}}\right.$ and $\left.\mathbf{2}-\mathbf{N} \mathbf{O}_{2}\right)$ show fast response time, excellent selectivity and sensitivity for the detection of $\mathrm{H}_{2} \mathrm{~S}$ under physiological conditions (HEPES buffer, $\mathrm{pH}$ 7.4) through fluorescence 'turn-on' mechanism. The detection limits $(12.2 \mu \mathrm{M}$ for $\mathbf{1}^{\prime}-\mathrm{N}_{3}$ and $34.8 \mu \mathrm{M}$ for $\mathbf{2}^{\prime}-\mathbf{N O}_{2}$ ) of both materials lie within the range of $\mathrm{H}_{2} \mathrm{~S}$ concentration observed in the biological systems. The materials can selectively detect $\mathrm{H}_{2} \mathrm{~S}$ even in the presence of other competing biomolecules. ${ }^{[33]}$ Chen reported a coordination polymer nanoparticle composing of $\mathrm{Tb}^{3+}$ ions, $\mathrm{Ag}^{+}$ions, and adenosine monophosphate, where the fluorescence of $\mathrm{Tb}^{3+}$ ions was sensitized by $\mathrm{Ag}^{+}$ ions. ${ }^{\left[{ }^{[4]}\right.}$ When $\mathrm{H}_{2} \mathrm{~S}$ was introduced, a fluorescence quenching would be observed because of strong affinity of $\mathrm{H}_{2} \mathrm{~S}$ to $\mathrm{Ag}^{+}$ions. In addition, Ma et al. also reported a heterogeneous nano MOF fluorescence probe for highly selective and sensitive detection of $\mathrm{H}_{2} \mathrm{~S}$ in living cells. Legrand et al. reported the designed MOF-based system achieving in vitro $\mathrm{H}_{2} \mathrm{~S}$ dosing by turn-on fluorescence with unprecedented sensitivity, and Li et al. have designed and synthesized a novel porous polymeric fluorescence probe, MN-ZIF-90, for quantitative $\mathrm{H}_{2} \mathrm{~S}$ fluorescent detection. ${ }^{[35]}$

\section{Sensing of $\mathrm{CO}_{2}$}

Pentyala investigated the gas sensing behavior of $\mathrm{Mg}$ - and Co-MOF-74 towards $\mathrm{CO}_{2}$ by means of work function based readout with Kelvin Probe. ${ }^{[36]}$ The observed changes in work function were explained in field of interactions between open metal sites of Mg-MOF-74 coordinated with water and gas molecules.

\section{Sensing of $\mathrm{O}_{2}$}

Highly-sensitive sensors for trace oxygen analytes are demanded in many oxygen-free environments, such as medical environment, chemical industry, and so on. Lin et al. reported the first luminescent MOFs for $\mathrm{O}_{2}$-sensing, by using bridging ligands derived from classic phosphorescent precious metal complexes. By connecting $\mathrm{Zn}$ (II) with two metalloligands derived from a common $\mathrm{O}_{2}$ sensitive complex $\operatorname{Ir}(\text { ppy })_{3}$ (ppy=2-phenylpyridine), three phosphorescent MOFs were synthesized. ${ }^{[37]}$ At 1 bar $\mathrm{O}_{2}$, the luminescence quenching efficiencies for the three MOFs and the two ligands are in the range of $32 \%-59 \%$ and $8 \%-16 \%$, respectively, in which the tetranuclear-based structure showing the highest efficiency of $59 \%$. Moreover, Chen synthesized a $\mathrm{Cu}(\mathrm{I})$-triazolate $[\mathrm{Cu}(\mathrm{detz})]$ (Hdetz=3,5-diethyl-1,2,4-trizole) NMOF, which was not luminescent in air due to the quenching effect by oxygen. ${ }^{[38]}$

\section{Sensing of other gas molecules}

A classic anionic metal-organic framework [bio-MOF-1, $\mathrm{Zn}_{8}(\mathrm{ad})_{4}(\mathrm{BPDC})_{6} \mathrm{O} \cdot 2 \mathrm{Me}_{2} \mathrm{NH}_{2} \quad$ (BPDC=biphenyl-4,4'-dicarboxylate, $\mathrm{Ad}=$ adeninate) $]$ encapsulated by $\mathrm{Eu}^{3+}-\beta$-diketonate complex via cation exchange can be used for sensing volatile amines, which is of great significance in environment and industrial monitor. ${ }^{[39]}$ MIL-101(Cr) nanoparticles were successfully HF-free synthesized via hydrothermal method. Then resistive humidity sensor was fabricated to investigate humidity sensing properties. ${ }^{[40]}$ The response time 
and recovery time are $17 \mathrm{~s}$ and $90 \mathrm{~s}$, respectively, which illustrates that porous MIL-101(Cr) nanoparticles have great potential to be used as humidity sensing materials.

\section{Sensing of $\mathrm{pH}$ value}

One of the significant subjects in MOF-based chemical sensors is the detection of $\mathrm{pH}$ values in aqueous solution, especially for monitoring subtle $\mathrm{pH}$ changes in biological environments and living cells. Qi et al. used lanthanide $\mathrm{Tb}^{3+}$ ions and small molecular ligands to design and assemble a kind of $\mathrm{pH}$-sensitive MOF nanoparticle based on intramolecular-charge-transfer effect. ${ }^{[41]}$ This kind of made-toorder MOF nanoparticle for $\mathrm{H}^{+}$is highly specific and sensitive and could be used to indicate fluorescently $\mathrm{pH}$ value of strong acidic solution via preset mechanism through luminescence of $\mathrm{Tb}^{3+}$. Otherwise, a strategy utilizing mixed-lanthanide metal-organic frameworks (MOFs) for self-referencing and colorimetric luminescent $\mathrm{pH}$ sensing has been developed. The mixed-lanthanide MOFs $\mathrm{Eu}_{x} \mathrm{~Tb}_{1-x} \mathrm{Hdpda}$ $\left[x=0.097,0.205,0.303, \mathrm{H}_{4} \mathrm{dpda}=4\right.$-(3,5-dicarboxyphenyl)pyridine2,6-dicarboxylic acid] exhibit excellent stability in phosphate buffer solution with $\mathrm{pH}$ values varying from 3.90 to $7.500^{[42]}$ Aguilera-Sigalat et al. reported firstly the pH-dependent fluorescence of UiO-66- $\mathrm{NH}_{2}$ across the wide range from 1 to $9 .{ }^{[43]}$ By application of a postsynthetic modification (PSM) diazotisation strategy, they synthesizeda new material, UiO-66-N=N-ind, which shows increased chemical stability and enhanced sensing up to $\mathrm{pH} 12$.

\section{Sensing of temperature}

A luminescent lanthanide metal-organic framework (MOF) based on $\mathrm{Eu}^{3+}$ and $\mathrm{Tb}^{3+}$ ions with 2-phenylsuccinate (EuTb-psa) was obtained solvothermally to explore its behavior as a temperature sensor in an unconventional temperature range from 13.5 to $313.5 \mathrm{~K}^{\left[{ }^{[44]}\right.}$ The first single-lanthanide MOFs ratiometric luminescent thermome$\operatorname{ter}\left(\mathrm{Me}_{2} \mathrm{NH}_{2}\right)_{3}\left[\mathrm{Eu}_{3}(\mathrm{FDC})_{4}\left(\mathrm{NO}_{3}\right)_{4}\right] \cdot 4 \mathrm{H}_{2} \mathrm{O}$ has been prepared. ${ }^{[45]}$ Due to the suitable triplet excited state energy of the ligand (the difference between the $T_{1}$ and ${ }^{5} \mathrm{D}_{0}$ levels of $\mathrm{Eu}^{3+}$ is lower than $1500 \mathrm{~cm}^{-1}$ ), the $\mathrm{Eu}^{3+}$ to the ligand triplet emission intensity ratio allows measuring the temperature in the $12-320 \mathrm{~K}$ range, with a relative thermal sensitivity up to $2.7 \% \mathrm{~K}^{-1}$ at $170 \mathrm{~K}\left(0.33 \% \mathrm{~K}^{-1}\right.$ at $\left.300 \mathrm{~K}\right)$ and a repeatability up to $96 \%$. In binary co-doped system, $\mathrm{Eu}_{0.0066} \mathrm{~Tb}_{0.9934} \mathrm{~L}$ and $\mathrm{Eu}_{0.0089} \mathrm{~Tb}_{0.9911} \mathrm{~L} \quad\left(\mathrm{H}_{4} \mathrm{~L}=2,6\right.$-di(2',4'-dicarboxylpheny)pyridine) show good linear responses to temperature with high sensitivities over a very wide range (from $77 \mathrm{~K}$ to $450 \mathrm{~K}$ ) (Figure 9), of which $\mathrm{Eu}_{0.0066^{-}}$ $\mathrm{Tb}_{0.9934} \mathrm{~L}$ exhibits a maximum relative sensitivity $\left(\mathrm{S}_{\mathrm{m}}\right)$ of $3.76 \% \mathrm{~K}^{-1}$ at $450 \mathrm{~K}^{[46]}$ The value is comparable to those of other excellent LnMOF thermometers reported recently whereas the response temperature range is greatly enlarged.
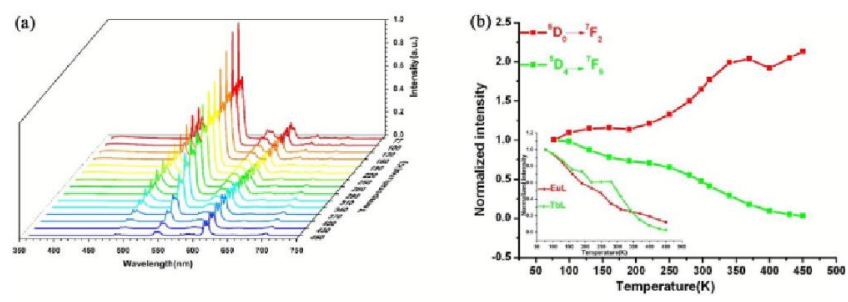

Figure 9 (a) Solid-state emission spectra of $\mathrm{Eu}_{0.0066} \mathrm{~Tb}_{0.9934} \mathrm{~L}$ recorded between $77 \mathrm{~K}$ and $450 \mathrm{~K}$ excited at $335 \mathrm{~nm}$; (b) Temperaturedependent normalized emission intensity of the ${ }^{5} \mathrm{D}_{4} \rightarrow{ }^{7} \mathrm{~F}_{5}$ and ${ }^{5} \mathrm{D}_{0} \rightarrow$ ${ }^{7} \mathrm{~F}_{2}$ transitions of $\mathrm{Eu}_{0.0066} \mathrm{~Tb}_{0.9934} \mathrm{~L}$.

\section{Conclusions}

Luminescent MOFs are an exactly fascinating class of multifunctional chemosensors through the unique performance of MOF mate- rials with suitable porosity, specific functional groups, higher quantum yield, and tunable luminescent properties. Although at the early stage of their development, luminescent MOFs have been a versatile and remarkable type of chemical sensors for the detection of ions, nitro explosives, gas molecules, $\mathrm{pH}$ value, and temperature.

While luminescent MOFs hold great promises for chemical sensing, there are important issues that should be addressed in the area of chemical sensing. First of all, a major challenge is to pre-design novel MOF materials with desired properties. Any specific application can theoretically be realized through the rational design of MOF materials in the terms of compositions, shapes, porosity, and luminescent properties. Secondly, the majority of MOF sensors are based on the monitoring of emission intensity changes in a single emission peak by a fluorometer. The accuracy can be heavily affected by the optoelectronic drifts of excitation power and detectors. Thirdly, most of them can only be used in organic solvents due to their poor stability in aqueous solution. Forthly, these materials often sense more than two targeted analytes simultaneously. An improved approach is to couple luminescent MOFs with other methods of signal transduction, such as interferometry, localized surface plasmon resonance (LSPR), and electrical/electrochemical/mechanical schemes, developing multifunctional MOFs for the diverse chemosensory applications. ${ }^{[1]}$ Briefly, luminescent MOFs will be extensively pursued for their practical applications in chemical sensing.

\section{Acknowledgements}

This work was supported by the Priority Academic Program Development of Jiangsu Higher Education Institutions (PAPD, No. YX03001), the Jiangsu Province Double Innovation Talent Program (No. 090300014001), and the Nanjing University of Posts \& Telecommunications (No. NY212004).

\section{References}

[1] (a) Ren, X. Y.; Lu, L. H. Chin. Chem. Lett. 2015, 26, 1439; (b) Heine, J.; Mueller-Buschbaum, K. Chem. Soc. Rev. 2013, 42, 9232.

[2] (a) Lustig, W. P.; Mukherjee, S.; Rudd, N. D.; Desai, A. V.; Li, J.; Ghosh, S. K. Chem. Soc. Rev. 2017, 46, 3242; (b) Kreno, L. E.; Leong, K.; Farha, O. K.; Allendorf, M.; Van Duyne, R. P.; Hupp, J. T. Chem. Rev. 2012, 112, 1105 .

[3] (a) Gao, J. K.; Ye, K. Q.; Yang, L.; Xiong, W. W.; Ye, L.; Wang, Y.; Zhang, Q. C. Inorg. Chem. 2014, 53, 691; (b) Xiong, W. W.; Zhang, Q. C. Angew. Chem. Int. Ed. 2015, 54, 11616.

[4] Allendorf, M. D.; Bauer, C. A.; Bhakta, R. K.; Houk, R. J. T. Chem. Soc. Rev. 2009, 38, 1330.

[5] (a) Vermeulen, N. A.; Karagiaridi, O.; Sarjeant, A. A.; Stern, C. L.; Hupp, J. T.; Farha, O. K.; Stoddart, J. F. J. Am. Chem. Soc.2013, 135, 14916; (b) Bhattacharyya, S.; Chakraborty, A.; Jayaramulu, K.; Hazra, A.; Maji, T. K. Chem. Commun. 2014, 50, 13567; (c) Bernini, M. C.; Fairen-Jimenez, D.; Pasinetti, M.; RamirezPastor. A. J.; Snurr, R. Q. J. Mater. Chem. B 2014, 2, 766; (d) Wu, Y. P.; Zhou, W.; Dong, W. W. Zhao, J.; Qiao, X. Q.; Hou, D. F.; Li, D. S.; Zhang, Q. C.; Feng, P. Y. Cryst. Growth. Des. 2017, $17,2158$.

[6] (a) Li, H. H.; Niu, Z.; Han, T.; Zhang, Z. J.; Shi, W.; Cheng, P. Sci. China Chem. 2011, 54, 1423; (b) Lin, J. M.; He, C. T.; Liao, P. Q.; Zhou, D. D.; Zhang, J. P.; Chen, X. M. Sci. China Chem. 2016, 59, 970.

[7] (a) Manna, K.; Zhang, T.; Lin, W. B. J. Am. Chem. Soc. 2014, 136, 6566; (b) Wu, Y. P.; Wu, X. Q.; Wang, J. F.; Zhao, J.; Dong, W. W.; Li, D. S.; Zhang, Q. C. Cryst. Growth. Des. 2016, 16, 2309.

[8] Horcajada, P.; Serre, C.; Maurin, G.; Ramsahye, N. A.; Balas, F.; ValletRegí, M.; Sebban, M.; Taulelle, F.; Férey, G. J. Am. Chem. Soc. 2008, 130, 6774 .

[9] (a) Wanderley, M. M.; Wang, C.; Wu, C. D.; Lin, W. J. Am. Chem. Soc. 2012, 134, 9050; (b) Guo, Y.; Feng, X.; Han, T.; Wang, S.; Lin, Z.; Dong, Y.; Wang, B. J. Am. Chem. Soc. 2014, 136, 15485; (c) Zhao, J.; Dong, W. 
W.; Wu, Y. P.; Wang, Y. N.; Wang, C. Li, D. S.; Zhang, Q. C. J. Mater. Chem. A 2015, 3, 6962; (d) Gao, J. K.; Ye, K. Q.; He, M.; Xiong, W. W.; Cao, W. F.; Lee, Z. Y.; Wang, Y.; Wu, T.; Huo, F. W.; Liu, X. G.; Zhang, Q. C. J. Solid. Chem. 2013, 206, 27; (e) Lu, H. S.; Bai, L. L.; Xiong, W. W.; Li, P. Z.; Ding, J. F.; Zhang, G. D.; Wu, T.; Zhao, Y. L.; Lee, J. M.; Yang, T. H.; Geng, B. Y.; Zhang, Q. C. Inorg. Chem. 2014, 53, 8529; (f) Zhao, J.; Wang, Y. N.; Dong, W. W.; Wu, Y. P.; Li, D. S.; Liu, B.; Zhang, Q. C. Chem. Comm. 2015, 51, 9479; (g) Gao, J. K.; He, M.; Lee, Z. Y.; Cao, W. F.; Xiong, W. W.; Li,Y. X.; Ganguly, R.; Wu, T.; Zhang, Q. C. Dalton. Trans. 2013, 42, 11367.

[10] Hu, Z. C.; Deibert, B. J.; Li, J. Chem. Soc. Rev. 2014, 43, 5815.

[11] Zhang, X. L.; Bing, Y. Y.; Gao, P.; Bai, H.; Hu. M. Inorg. Chim. Acta 2017, 455,98

[12] Wang, F. Q.; Yu, Z. C.; Wang, C. G.; Xu, K. H.; Yu, J. G.; Zhang, J. X.; Fu, Y. Y.; Li, X. Y.; Zhao, Y. N. Sens. Actuators. B 2017, 239, 688.

[13] Zhou, X. H.; Zhu, Y. L.; Li, L.; Yang, T.; Wang, J.; Huang, W. Sci. China Chem. 2017, 60, 1130.

[14] Zhu, X. D.; Yong Li, Y.; Zhou, W. X.; Liu, R. M.; Ding, Y. D.; Lü, J.; Proserpioc, D. M. CrystEngComm 2016, 18, 4530.

[15] Yang, Y. J.; Wang, M. J.; Zhang, K. L. J. Mater. Chem. C 2016, 4, 11404.

[16] Wang, B.; Yang, Q.; Guo, C.; Sun, Y.; Xie, L. H.; Li, J. R. ACS. Appl. Mater. Interfaces 2017, 9, 10286 .

[17] Ming, M.; Bai, N. Inorg. Chem. Comm. 2017, 75, 37.

[18] Dong, Y.; Zhang, H.; Lei, F.; Liang, M.; Qian, X.; Shen, P.; Xu, H.; Chen, Z.; Gao, J.; Yao, J. J. Solid. State Chem. 2017, 245, 160.

[19] Wu, Y.; Yang, G. P.; Zhou, X.; Li, J.; Ning, Y.; Wang, Y. Y. Dalton Trans. 2015, 44, 10385.

[20] Xing, S.; Bing, Q.; Song, L.; Li, G.; Liu, J.; Shi, Z.; Feng, S.; Xu, R., Chem. 2016, 22, 16230 .

[21] Zhang, S. T.; Yang, J.; Wu, H.; Liu,Y. Y.; Ma, J. F. Chem. Eur. J. 2015, 21 , 15806.

[22] Li, L.; Chen, Q.; Li, G. N.; Niu, Z. G.; Zhou, X. H.; Yang, T.; Huang, W. J. Mater. Chem. C 2016, 4, 1900

[23] Lin, X. P.; Hong, Y. H.; Zhang, C.; Huang, R. Y.; Wang, C.; Lin, W. B. Chem. Commun. 2015, 51, 16996.

[24] Luo, J.; Liu, B. S.; Cao, C.; Wei, F. Inorg. Chem. Commun. 2017, 76, 18.

[25] Liu, B.; Wu, W. P.; Hou, L.; Wang, Y. Y. Chem. Commun. 2014, 50, 8731.

[26] Hao, J. N.; Yan, B. J. Mater. Chem. A 2015, 3, 4788.
[27] Sun, N. N.; Yan, B. Phys. Chem. Chem. Phys. 2017, 19, 11708.

[28] Zhang, L.; Jian, Y.; Wang, J.; He, C.; Li, X.; Liu, T.; Duan, C. Dalton Trans. 2012, 41, 10153.

[29] Cao, J. W.; Gao, Y. F.; Wang, Y. Q.; Du, C. F.; Liu, Z. L. Chem. Commun. 2013, 49, 6897.

[30] Huang, Q.; Wang, J.; Wang, Q.; Li, G. Supramol. Chem. 2016, 29, 193.

[31] Liu, F. H.; Qin, C.; Ding, Y.; Wu, H.; Shao, K. Z.; Su, Z. M. Dalton Trans. 2015, 44, 1754

[32] Xu, G. W.; Wu, Y. P.; Dong, W. W.; Zhao, J.; Wu, X. Q.; Li, D. S.; Zhang, Q. C. Small 2017, 1602996.

[33] Buragohaina, A.; Biswas, S. CrystEngComm 2016, 18, 4374.

[34] Liu, B. X.; Chen, Y. Anal. Chem. 2013, 85, 11020.

[35] (a) Ma, Y.; Su, H.; Kuang, X.; Li, X.; Zhang, T.; Tang, B. Anal. Chem. 2014, 86, 11459; (b) Legrand, A.; Pastushenko, A.; Lysenko, V.; Geloen, A.; Quadrelli, E. A.; Canivet, J.; Farrusseng, D. ChemNanoMat 2016, 2, 866; (c) Li, H.; Feng, X.; Guo, Y.; Chen, D.; Li, R.; Ren, X.; Jiang, X.; Dong, Y.; Wang, B. Sci. Rep. 2014, 4, 4366.

[36] Pentyalaa, V.; Davydovskayab, P.; Pohlec, R.; Urbana, G.; Yurchenkoa, O. Procedia Eng. 2014, 87, 1071.

[37] Xie, Z.; Ma, L.; deKrafft, K. E.; Jin, A.; Lin, W. J. Am. Chem. Soc. 2010, $132,922$.

[38] Liu, S. Y.; Qi, X. L.; Lin, R. B.; Cheng, X. N.; Liao, P. Q.; Zhang, J. P.; Chen, X. M. Adv. Funct. Mater. 2014, 24, 5866.

[39] Shen, X.; Yan, B. J. Mater. Chem. C 2015, 3, 7038

[40] Zhang, J. J.; Sun, L.; Chen, C.; Liu, M.; Dong, W.; Guo, W. B.; Ruan, S. P. J. Alloy. Compd. 2017, 695, 520.

[41] Qi, Z.; Chen, Y. Biosens. Bioelectron. 2017, 87, 236.

[42] Xia, T. F; Cui, Y. J.; Yang, Y.; Qian, G. D. ChemNanoMat 2017, 3, 51.

[43] Aguilera-Sigalat, J.; Bradshaw, D. Chem. Commun. 2014, 50, 4711.

[44] Gomez, G. E.; Kaczmarek, A. M.; Van Deun, R.; Brusau, E. V.; Narda, G. E.; Vega, D.; Iglesias, M.; Gutierrez-Puebla, E.; Monge, M. Á. Eur. J. Inorg. Chem. 2016, 10, 1577.

[45] Li, L.; Zhu, Y. L.; Zhou, X. H.; Brites, C. D. S.; Ananias, D.; Lin, Z.; Paz, F. A. A.; Rocha, J.; Huang, W.; Carlos, L. D., Adv. Funct. Mater. 2016, 26, 8677.

[46] Yang, Y.; Chen, L.; Jiang, F. L.; Yu, M. X.; Wan, X. Y.; Zhang, B.; Hong, M. C. J. Mater. Chem. C 2017, 5, 1981. 